\title{
Ethics of Seclusion Usage among Aggressive Patients in Psychiatric Setting
}

\author{
Qusai Al harahsheh* \\ The Hashemite University, Jordan
}

*Corresponding author: Qusai $\mathrm{Al}$ harahsheh, The Hashemite University, School of Nursing, Jordan.

Received Date: September 21, 2020

Published Date: October 08, 2020

\section{Introduction}

Every person in our world adapt with life challenges in different way, some people cannot develop ways to cope with this challenges which resulted to mental disorders among this persons as a chain of destructive behaviors images, this behaviors affect patients and staff safety, someone use seclusion to control this behaviors, others may use medications, communication skill and de-escalating techniques.

In Jordan, mental and psychiatric science developed many methods to control this destructives behaviors such as medication, technique, and seclusion, the point here about ethics of using seclusion among in-patients, is it acceptable or not? Seclusion defined as involuntary isolation of patient in specific room, this room named as seclusion room, and has many characteristics focusing on non-stimulating place, it must be locked, supervised by window, and contains the safety measurements as a whole (Health Care Commission, 2008). On the other hand the mental health commission defined the seclusion as a place has locked door designed in way which prevent him from going outside, the main reason to use seclusion is to protect patient and others safety as most of studies mentioned, although there are many other alternatives may use to meet this goals such as de-escalating technique.

Actually ethical consideration against seclusion are not newly identified, in 1839 the British psychiatrist John Connolly advocate to eliminate the seclusion from treatment, because it's penetrate many of most important patient rights (Colonize, 2005). Many studies and institutions fight to discourage of using seclusion among mentally ill patient depend on legal and ethical powers and ethical principles such as patient rights to refuse treatment, autonomy, humanity, and dignity.

Although many opinions focusing on the harm effects of using seclusion related to break the autonomy, humanity and many other principles, many studies shown that seclusion as one of the most important measurement used in close units for mental health patients as a result of aggressive behaviors which may affect patient his self, other patients and health care provides who working on this settings (Happell \& Harrow, 2010). Moreover the number of seclusion episode varied from 37 -110/1000 in patient/day in USA and Netherlands, and 13 - 151.7/1000 patient/day in Australia, Belgium [1]. On the other hand, the failure of using the psychotropic agent in 1950 to control aggression behaviors pushed health care providers to use seclusion as essential elements to treat mentally ill patient (Guthrie, 1978).

The international recommendations considered the seclusion as emergency measures provided to prevent any incidence of violence or injuries for staff and patients [2], the point here why this staff didn't use other alternatives before and after aggressive or violence situations. Furthermore, study about the legal and ethical aspect of seclusion which done in Australia concluded that seclusion must be used to managed the aggressive behaviors for patient in psychiatric sittings [3].

Actually there is no specific law prevents using of seclusion in Jordan, but regarding to Mental Health Patient Right Association which placed in Quebec, they order hospitals to take stock of 
seclusion practice and advise them to use alternative measures [4], the point here what the barriers of Ministry of Health in Jordan that prevent it of taking same decision.

Using seclusion still large ethical dilemma because its acting against patient autonomy (Prinsen \& Van Delden, 2009), on the same time using seclusion considered as distractive of patient rights to make personal dissection or choose the preferred way of treatment [5], furthermore some patient considered seclusion as unnecessary, extra intervention and sometimes it may has not any benefits for them [2] and it's may cause emotional trauma and distress for patient and staff [6], for this reasons the new since directed to develop other alternatives rather than seclusion usage.

The most important point which can prevent any staff to seclude any patient is that nursing and medical ethics working together on respect the dignity and autonomy of patient by providing choices, not by paternalistic practice (Holmes et al., 2004) as un-qualified psychiatric nurses doing, moreover the WHO recommended involving patients in caring process under concordance concept by let him to choose the type of treatment, which finally increases the quality of life of patient (WHO, 2009 [7]) which considered as a goal of effective psychiatric nurses in Jordan and everywhere. Furthermore around $62 \%$ of seclusion incidence occurred as a result of actually threating violence (El-Badri \& Mellso, 2002); on this point using seclusion is recommended for this emergency situation if other alternatives failed to avoid this threat (Tardiff \& Lion, 2008), its fine but it's better to avoid the incidence from the beginning by communication skills, avoiding the triggers which act in incasing the aggressiveness among patients and other alternatives [8-12].

Finally, what about providing trainings and courses about communication skills, de-escalating techniques which considered as very useful alternative to control aggressiveness and other alternative measures for staff who are working on psychiatric field to decrease using of seclusion?, what about providing trainings to staff about how to prevent triggers, stimulus of aggressiveness and violence, giving appropriate medications on appropriate time with appropriate diet which may eliminate or at least decrease using of seclusion among Jordanian psychiatric sittings?, why not starting apply this solutions in Jordan, on the same time improving staffing criteria in Jordanian psychiatric centers such as prevent any staff from working in psychiatric sittings if he/she didn't pass in specific exams and interviews which applied by the most expert persons in psychiatric and mental health field in Jordan such as PhD carriers, on that time using seclusion may decrease related to other skills which founded among qualified nurses, what about qualified staff who traveled outside of Jordan related to low salaries, disrespect and very poor motivations push them to still help Jordanian patients among Jordanian psychiatric centers?.

\section{Acknowledgement}

None.

\section{Conflict of Interest}

No conflict of interest.

\section{References}

1. Janssen WA, Noorthoorn EO, de Vries WJ, Hutschemeakers GJM, Lendemeijer HHGM, et al. (2008). The use of seclusion in the Netherlands compared to countries in and outside Europe. International Journal of Law and Psychiatry 31(6): 463-470.

2. Soininen P, Välimäki M, Noda T, Puukka P, Korkeila J, et al. (2013) Secluded and restrained patients' perception of their treatment. Int J Ment Health Nurs 22: 47-55.

3. Muir-Cochrane EC, Holmes CA (2001) Legal and ethical aspects of seclusion Australian Perspective. Journal of Psychiatric and Mental Health Nursing 8: 501-506.

4. AGIDD (1999) Actes du colloque international sur l'isolement et la contention: Pours'en sortirets'en défaire. AGIDD-SMQ Montréal, Québec.

5. Finlex (2009a) Laki potilaan asemasta ja oikeuksista. Act on the status and rights of patient.

6. Frueh BC, Knapp RG, Cusack KJ, Anouk L Grubaugh, Julie A Sauvageot, et al (2005) Patients reports of traumatic or harmful experiences within the psychiatric setting. Psychiatric Services 56: 1123-1133.

7. World Health Organization (2009) Policies and practices for mental health in Europe-meeting the challenges. Denmark: WHO Regional Office for Europe.

8. Mental Health Commission (2011a) Annual Report 2010 including Report of the Inspector of Mental Health Services (Dublin: MHC.) O'Hagan M, Divis M and Running head: SECLUSION USAGE AMONG AGGRESSIVE PATIENTS.

9. Long J (2008) Best practice in the reduction and elimination of seclusion and restraint; Seclusion: time for change. (Auckland: Te Pou Te Whakaaro Nui: the National Centre of Mental Health Research, Information and Workforce Development).

10. Prinsen EJ, van Delden JJ (2009) Can we justify eliminating coercive measures in psychiatry? Journal of Medical Ethics 35(1): 69-73.

11. Schreiner GM, Crafton CG, Sevin JA (2004) Decreasing the use of mechanical restraints and locked seclusion', in Administration and Policy in Mental Health 31: 449-463.

12. Townsend MC (2006) Essentials of psychiatric mental health nursing: Concepts of care in evidence-based practice (4th ed.). Philadelphia, PA: F.A. Davis, USA 